\title{
The Role of the Locus Coeruleus and N-Methyl-D-Aspartic Acid (NMDA) and AMPA Receptors in Opiate Withdrawal
}

Kurt Rasmussen, Ph.D.

Biochemical, behavioral, and electrophysiologic studies indicate that activation of the noradrenergic cells in the locus coeruleus (LC) plays an important role in the symptoms of opiate withdrawal. Extrinsic factors play a major role in the morphine-withdrawal-induced activation of the LC, but intrinsic factors also play a role. Among the extrinsic factors, a glutamatergic projection from the nucleus paragigantocellularis plays an important role in the withdrawal-induced activation of the LC.

$N$-methyl-D-aspartic acid (NMDA) receptors play at most a minor role in the withdrawal-induced activation of the LC by glutamate; preliminary evidence indicates that $\alpha$-amino-3-hydroxy-5-methyl-4-isoxazole propionic acid (AMPA) receptors play an important role. Whereas NMDA antagonists produce little to no suppression of the activation of the LC during morphine withdrawal, they do suppress many morphine withdrawal symptoms. However, phencyclidinelike side effects may limit the clinical utility of NMDA antagonists. Experiments examining c-fos expression during morphine withdrawal

KEY WORDS: Opiate withdrawal; Locus coeruleus; NMDA; AMPA

In humans, abstinence from the chronic administration of opiates results in a characteristic morbidity including anxiety, nausea, insomnia, hot and cold flashes,

From the Lilly Research Laboratories, Eli Lilly and Ecompany, In dianapolis, IN

Address correspondence to: Kurt Rasmussen, Ph.D., Lilly Research Laboratories, Eli Lilly and Company, Lilly Corporate Center, Indianapolis, IN 46285.

Received December 22, 1994; revised April 19. 1995; accepted Mav 3, 1995 indicate that NMDA antagonists may exert some of their influence on morphine withdrawal symptoms through actions in the forebrain. Pretreatment with the noncompetitive NMDA antagonist MK801 blocks morphine withdrawal-induced increased c-fos expression in the amygdala, but not in the nucleus accumbens, frontal cortex, or hippocampus. Pretreatment with the competitive NMDA antagonist LY274614 (or the $\alpha_{2}$-adrenergic agonist clonidine) blocks morphine withdrawal-induced increased c-fos expression in the amygdala and nucleus accumbens, but not in the frontal cortex or hippocampus. These results help to elucidate some of the neuroanatomy and neurophysiology underlying morphine withdrawal. Further, NMDA antagonists may not be clinically useful for opiate withdrawal due to their side-effects, but AMPA antagonists may be of great benefit for alleviating opiate withdrawal symptoms in humans.

[Neuropsychopharmacology 13:295-300, 1995]

muscle aches, perspiration, and diarrhea (Kolb and Himmelsbach 1938). The neurophysiology underlying these opiate withdrawal symptoms is not completely understood. Several neurotransmitter systems have been shown to play an important role in opiate withdrawal including the dopaminergic (Pothos et al. 1991; Harris and Aston-Jones 1994) and cholinergic (Buccafusco 1991, 1992) systems. Two other neurotransmitter systems whose interactions have been proposed to play a major role in opiate withdrawal are the glutamatergic and noradrenergic systems.

Studies of the role of the noradrenergic system in 
opiate withdrawal have focused on the locus coeruleus (LC), the largest cluster of noradrenergic neurons in the mammalian brain (Dahlstrom and Fuxe 1965; Foote et al. 1983). Whereas the cell bodies of the LC are confined to a small section of the pons, its neurons send extensive projections throughout the central nervous system, including the cerebral cortex, hippocampus, cerebellum, and spinal cord (Jones and Moore 1977; Nygren and Olson 1977). Autoradiographic studies have shown that the LC possesses a high density of opiate receptors, particularly of the mu and kappa subtype (Pert et al. 1975; Tempel and Zukin 1987). Single-unit recordings in anesthetized or awake rats have shown that LC neurons are inhibited by local or systemic administration of opiates (Korf et al. 1974; Bird and Kuhar 1977; Aghajanian 1978; Valentino and Wehby 1988). In addition, in awake cats, local (but not systemic) administration of opiates decreases the activity of LC neurons (Rasmussen and Jacobs 1985; Abercrombie et al. 1988).

The role of the noradrenergic system in opiate withdrawal is supported by a variety of behavioral, biochemical, and electrophysiologic studies. For example, in opiate-dependent rats, there is a marked increase in fring of LC neurons during antagonist precipitated withdrawal (Aghajanian 1978; Valentino and Wehby 1989; Rasmussen et al. 1990; Akaoka and Aston-Jones 1991), and an increase in norepinephrine turnover and release in LC projection areas (Crawley et al. 1979; Rasmussen et al. 1991b; Done et al. 1992). This increase in activity of LC neurons has been hypothesized to play an important role in opitate withdrawal symptoms because: (1) the increased unit activity correlates temporally with withdrawal behaviors (Rasmussen et al. 1990); (2) systemic administration and local infusion of clonidine, an $\alpha_{2}$-adrenergic receptor agonist, into the LC suppresses the increased LC unit activity (Aghajanian 1978), the increase in norepinephrine turnover and release in LC projection areas (Laverty and Roth 1980; Done et al. 1992) and many behavioral symptoms (Tseng et al. 1975; Gold et al. 1978; Taylor et al. 1988) seen during opiate withdrawal; (3) destruction of the LC decreases physical signs of opiate withdrawal (Maldonado and Koob 1993); and (4) the most sensitive site for the induction of withdrawal signs following the local injection of an opiate antagonist is the LC (Maldonado et al. 1992).

Extrinsic factors play a major role in the morphinewithdrawal-induced activation of the LC, but intrinsic factors also play a role. Evidence for the role of intrinsic factors in the withdrawal-induced activation of the LC include: (1) chronic morphine administration leads to an up-regulation of the cAMP system within LC neurons (Rasmussen et al. 1990; Nestler 1992); and (2) both the baseline firing rate and the maximal responsiveness to CAMP analogues is elevated in LC neurons recorded in brain slices from morphine-dependent animals (Kogan et al. 1992). Conflicting reports exist on the effects of local infusion of naloxone on LC neuronal activity in morphine dependent animals, with one study reporting no change (Akaoka and Aston-Jones 1991) and another reporting an increase in activity (Aghajanian 1978). There are several lines of evidence supporting a role for excitatory amino acid afferents to the LC as extrinsic factors in the withdrawal activation of LC neurons. First, nonselective excitatory amino acid antagonists, after both ICV injection or direct infusion into the LC, attenuate the morphine-withdrawal-induced activation of LC neurons (Rasmussen et al. 1989, 1991a; Akaoka and Aston-Jones 1991). Second, lesions of the nucleus paragigantocellularis (PGi), the source of a major excitatory amino acid afferent to the LC, attenuate the morphine-withdrawal-induced activation of LC neurons (Rasmussen et al. 1989). Third, opiate withdrawal increases glutamate and aspartate efflux in the LC (Aghajanian et al. 1994; Zhang et al. 1994).

In an effort to determine which subtype of excitatory amino acid receptor plays a role in the withdrawalinduced increase in activity of LC neurons, we examined the effects of competitive and noncompetitive $\mathrm{N}$-methyl-D-aspartic acid (NMDA) antagonists on morphine-withdrawal symptoms and the withdrawal-induced activation of LC cells (Rasmussen et al. 1991b). Systemic administration of the noncompetitive NMDA antagonist MK801 dose dependently blocked the behavioral signs of withdrawal in morphine-dependent rats. However, the same doses of MK801 that blocked morphine withdrawal also simultaneously (and dose dependently) produced phencyclidine (PCP)like behavioral effects (for instance, head-weaving, falls, and increased locomotor activity). The competitive NMDA antagonist LY274614 also dose dependently blocked the behavioral signs of withdrawal in morphine-dependent rats but did not produce any PCPlike behavioral effects (although some sedation occurred at the higher tested doses). Single-unit recordings of LC neurons from morphine-dependent animals showed that neither MK801 nor LY274614 blocked the withdrawal-induced activation of these neurons. In addition, neither NMDA antagonist blocked the withdrawal-induced increase in norepinephrine turnover in the cortex, hippocampus, or hypothalamus. Thus, the LC-noradrenergic system appears to be fully activated in animals that are showing few overt signs of withdrawal due to pretreatment with an NMDA antagonist. It is important to note that these results do not necessarily indicate that the LC does not play a role in opiate withdrawal, as the NMDA antagonists may be blocking the effects of LC activation at a site distal to the LC. However, these results do indicate that suppression of LC unit activity is sufficient, but not necessary, for suppression of many opiate withdrawal symptoms. An additional possibility is that LC activation may be involved in some aspect(s) of with- 
drawal not measured in the study (for example, dysphoria).

Thus, NMDA antagonists (unlike the $\alpha_{2}$-agonist clonidine) attenuate many physical signs of morphine withdrawal without blocking the withdrawal-induced increase of LC unit activity. Therefore, these studies indicate that the excitatory amino acid induced activation of the LC during opiate withdrawal is not mediated primarily through NMDA receptors. Another study reported that direct injections of an NMDA antagonist into the LC produced only a modest ( $\sim 20 \%$ ), but significant, reduction in withdrawal-induced activation of the LC (Akaoka and Aston-Jones 1991). Consistent with this finding are results indicating that the excitatory amino acid projection to the $L C$ from the $P G$ is mediated by nonNMDA receptors (Ennis and AstonJones 1988). In addition, these results indicate that noncompetitive NMDA antagonists like MK801 may not be useful to alleviate opiate-withdrawal symptoms in humans because of their PCPlike side-effects. However, competitive NMDA antagonists like LY274614 may be able to alleviate opiate-withdrawal symptoms in man

If NMDA antagonists suppress morphine withdrawal symptoms without affecting the activity of the LC, where are the NMDA antagonists acting to inhibit morphine withdrawal symptoms? In an effort to explore this question, we examined the effects of NMDA antagonists (and clonidine) on the induction of c-fos in various central nervous system (CNS) regions during naltrexone-precipitated withdrawal in morphine-dependent rats. The nuclear protein Fos is a product of the c-fos proto-oncogene and appears to regulate the transcription of cellular genes (Curran et al. 1990; Morgan and Curran 1991; Sheng and Greenberg 1990; Sonnenberg et al. 1989; Zhu and Inturrisi 1993). The expression of c-fos mRNA and protein is rapidly stimulated in response to increases in neuronal activity. Thus, the presence of c-fos mRNA or protein has been used as a measure of neuronal activation in the CNS (Curran et al. 1990; Morgan and Curran 1991; Sheng and Greenberg 1990; Zhu and Inturrisi 1993). Recently, opiate withdrawal has been demonstrated to lead to an induction of the c-fos proto-oncogene and Foslike immunoreactivity in several regions of the rat brain (Hayward et al. 1990; Stornetta et al. 1993); many of these same brain regions have previously been reported to also increase glucose utilization during morphine withdrawal (Kimes and London, 1989).

Naltrexone-precipitated morphine withdrawal increased c-fos mRNA levels in the nucleus accumbens. frontal cortex, amygdala, and hippocampus, but not in the striatum or spinal cord. Pretreatment with the noncompetitive NMDA antagonist MK801 blocked the withdrawal-induced increased c-fos expression in the amygdala, but not in the nucleus accumbens, frontal cortex, or hippocampus (Rasmussen et al. 1995)
Pretreatment with the competitive NMDA antagonist LY274614, or the $\alpha_{2}$-adrenergic agonist clonidine, blocked the withdrawal-induced increased c-fos expression in the amygdala and nucleus accumbens, but not in the frontal cortex or hippocampus (Rasmussen et al. 1995). Because radioligand binding studies indicate that NMDA receptor sites are present in all four areas that showed increased c-fos expression during morphine withdrawal (Monaghan and Cotman 1985), these results indicate that the increased c-fos expression during morphine withdrawal seen in the amygdala and nucleus accumbens is mediated, at least in part, by activation of NMDA receptors; conversely, the increased c-fos expression during morphine-withdrawal seen in the hippocampus and frontal cortex does not seem to be mediated primarily by activation of NMDA receptors. Similarly, as $\alpha_{2}$-adrenergic binding sites are also present in the four areas that showed increased c-fos expression during morphine withdrawal (Unnerstall et al. 1984), $\alpha_{2}$-adrenergic receptors in the amygdala and nucleus accumbens, but not in the hippocampus or frontal cortex, may play a role in the morphine-withdrawal suppressing actions of clonidine. The suppression of the withdrawal-induced c-fos expression in the amygdala by clonidine parallels previous electrophysiologic findings showing that clonidine is able to reverse the increased firing rate of amygdala neurons that occurs during morphine withdrawal (Freedman and Aghajanian 1985).

It is interesting to note that clonidine, MK801, and LY274614 had largely similar effects on c-fos expression in morphine withdrawal despite different pharmacologic actions. These results suggest a role of the nucleus accumbens and amygdala in the withdrawal symptoms commonly attenuated by these compounds and a role for the hippocampus and frontal cortex in the withdrawal symptoms not attenuated by these compounds. Along these lines, it is interesting to note that the nucleus accumbens and the amygdala have been suggested to play an important role in the aversive effects of opiate withdrawal (Stinus et al. 1990), and that MK801 and clonidine have been shown to attenuate at least some aversive effects of opiate withdrawal (Higgins et al. 1992; Kosten 1994). Thus, the effects of MK801 and clonidine in the amygdala may play an important role in its ability to attenuate aversive effects of opiate withdrawal. Further studies are needed to examine the effects LY274614 on the aversive effects of morphine withdrawal. However, given its simultaneous effects on c-fos expression in the amygdala and nucleus accumbens, these results predict strong effects of LY274614 on the aversive effects of opiate withdrawal. In addition, it should also be noted that because each of the compounds used to alleviate withdrawal symptoms in this study has different behavioral side-effects (for example, sedation for LY274614, PCPlike effects for 


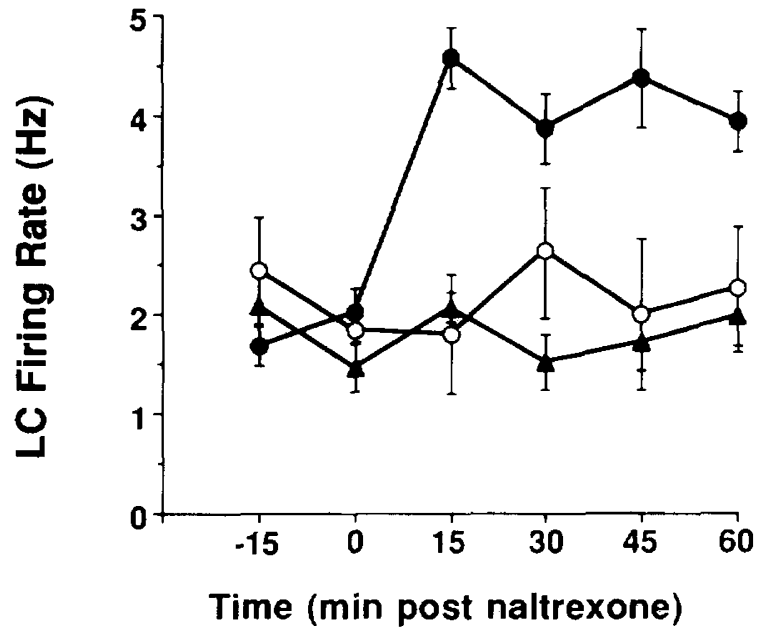

Figure 1. Effects of saline (SC, closed circles) or LY215490 (SC, $50 \mathrm{mg} / \mathrm{kg}$, open circles) pretreatment on the activity of locus coeruleus (LC) neurons during naltrexone-induced withdrawal in morphine-dependent, anesthetized rats. Activity of LC cells in animals receiving sham pellets is also shown (closed triangles). Values are expressed as mean $\pm \mathrm{SE}(n=4$ to 20 cells at each time point from two to six rats)

MK801, and excessive jumping for clonidine), these results indicate that the blockade of withdrawal symptoms by these compounds is unlikely to be simply due to any behavioral response competition.

The studies outlined in this article indicate that competitive NMDA antagonists may be useful for alleviating opiate-withdrawal symptoms in humans. However, recent reports indicate that competitive NMDA antagonists also produce PCPlike side-effects in humans (Sveinbjornsdottir et al. 1993; Grotta 1994). Further testing is needed to determine if any competitive NMDA antagonists will have beneficial therapeutic effects at doses below those causing side-effects. However, because the morphine-withdrawal induced activation of the LC seems to be mediated at least in part via nonNMDA receptors and if, as hypothesized, the $\mathrm{LC}$ plays an important role in morphine withdrawal symptoms, then nonNMDA excitatory amino acid antagonists should also be useful in alleviating morphine withdrawal symptoms. Indeed, recent experiments in our laboratory suggest that $\alpha$-amino-3-hydroxy-5-methyl4 -isoxazole propionic acid (AMPA) receptors may play an important role in the morphine withdrawal activation of LC neurons. Preliminary observations indicate that pretreatment with the selective AMPA antagonist LY215490 (Ornstein et al. 1993) attenuates the withdrawal-induced activation of LC neurons (Figure 1); a more detailed examination of the effects of AMPA antagonists on morphine withdrawal-induced activation of the LC is currently underway in our laboratory. Therefore, AMPA antagonists may be able to suppress opiate withdrawal symptoms in humans without producing the side-effects seen with NMDA antagonists. Extensive preclinical and clinical testing will be needed to evaluate the validity of this "AMPA" hypothesis. The effects of clonidine, LY274614, MK-801, and LY215490 on various signs of morphine withdrawal are summarized in Table 1.

In conclusion, several lines of evidence indicate that activation of the LC-noradrenergic system plays an important role in morphine withdrawal symptoms. The activation of the LC during morphine withdrawal seems to be mediated, at least in part, by nonNMDA excitatory amino acid receptors; preliminary evidence indicates these receptors may be AMPA receptors. Whereas NMDA receptors do not primarily mediate the withdrawal activation of the LC, they do play an important role in morphine withdrawal symptoms, as NMDA antagonists can block many of the symptoms of morphine withdrawal. In addition, NMDA antagonists can block the morphine withdrawal-induced c-fos activation in the amygdala and nucleus accumbens (but not frontal cortex or hippocampus). For the treatment of opiate withdrawal in man, PCPlike side effects may limit the usefulness of NMDA antagonists, but AMPA antagonists hold great promise as clinically relevent therapeutics. Extensive clinical tests will be needed to evaluate

Table 1. Effects of Various Compounds on Different Aspects of Morphine Withdrawal

\begin{tabular}{lcccc}
$\begin{array}{l}\text { Morphine } \\
\begin{array}{l}\text { Withdrawal } \\
\text { Sign }\end{array}\end{array}$ & $\begin{array}{c}\text { Clonidine } \\
\alpha_{2} \text {-Adrenergic } \\
\text { Agonist }\end{array}$ & $\begin{array}{c}\text { LY274614 } \\
\text { Competitive } \\
\text { NMDA } \\
\text { Antagonist }\end{array}$ & $\begin{array}{c}\text { MK-801 } \\
\text { Noncompetitive } \\
\text { NMDA } \\
\text { Antagonist }\end{array}$ & $\begin{array}{c}\text { LY215490 } \\
\text { AMPA } \\
\text { Antagonist }\end{array}$ \\
\hline $\begin{array}{l}\text { LC activation } \\
\text { Behavioral symptoms }\end{array}$ & $\downarrow$ & $\mathrm{NE}$ & $\mathrm{NE}$ & $\downarrow$ \\
$\begin{array}{l}\text { c-fos activation } \\
\text { Amygdala }\end{array}$ & $\downarrow$ & $\downarrow$ & $\downarrow$ & $?$ \\
N. accumbens & $\downarrow$ & $\downarrow$ & $\downarrow$ & $?$ \\
$\begin{array}{l}\text { Frontal cortex } \\
\text { Hippocampus }\end{array}$ & $\downarrow$ & $\downarrow$ & $\mathrm{NE}$ & $?$ \\
\hline
\end{tabular}

Abbreviations: $=$ decrease; $\mathrm{NE}=$ no effect ? - effect unknown 
the potential utility of these drugs as treatments for opiate withdrawal in humans.

\section{REFERENCES}

Abercrombie ED, Levine ES, Jacobs BL (1988): Microinjected morphine suppresses the activity of locus coeruleus noradrenergic neurons in freely moving cats. Neurosci Lett 86:334-338

Aghajanian GK (1978): Tolerance of locus coeruleus neurones to morphine and suppression of withdrawal response by clonidine. Nature 276:186-187

Aghajanian GK, Kogan JH, Moghaddam B (1994): Opiate withdrawal increases glutamate and aspartate efflux in the locus coeruleus: An in vivo microdialysis study. Brain Res 636:126-130

Akaoka H, Aston-Jones GA (1991): Opiate withdrawalinduced hyperactivity of locus coeruleus neurons is substantially mediated by augmented excitatory amino acid input. J Neurosci 11:3,830-3,839

Bird SJ, Kuhar MJ (1977): Iontophoretic application of opiates to the locus coeruleus. Brain Res 122:523-533

Buccafusco JJ (1991): Inhibition of the morphine withdrawal syndrome by a novel muscarinic antagonist (4-DAMP). Life Sci 48:749-756

Buccafusco JJ (1992): Neuropharmacologic and behavioral ac tions of clonidine: Interactions with central neurotransmitters. Int Rev Neurobiol 33:55-107

Crawley JN, Laverty R, Roth R (1979): Clondine reversal of increased norepinephrine metabolite levels during morphine withdrawal. Eur J Pharmacol 57:247-250

Curran T, Abate C, Cohen DR, Macgregor PF, Rauscher FJ 3d, Sonnenberg JL, Connor JA, Morgan JI (1990): Inducible proto-oncogene transcription factors: Third messengers in the brain. CSH Sym Quant Biol 55:225-234

Dahlstrom A, Fuxe K (1965): Evidence for the existence of monoamine-containing neurons in the central nervous system. I. Demonstration of monoamines in the cell bod ies of brainstem neurons. Acta Physiol Scand Suppl 232:1-55

Done C, Silverstone P, Sharp T (1492): Effect of naloxoneprecipitated morphine withdrawal on noradrenaline release in rat hippocampus in vivo. Eur I Pharmacol 215 333-336

Ennis M, Aston-Jones G (1988): Activatıon of locus coeruleus from nucleus paragigantocellularis: a new excitatory amino acid pathway in brain. I Neurosci 8:3,644-3,657

Foote SL, Bloom FE, Aston-Jones (; (1983): Nucleus locus coeruleus: New evidence of anatomic and physiologic specificity. Physiol Rev 63:844-914

Freedman JE, Aghajanian GK (1985): Opiate and $\alpha_{2-}$ adrenoceptor responses of rat amvgdaloid neurons: $\mathrm{Co}$ localization and interactions during withdrawal. I Neurosci 5:3,016-3,024

Gold MS, Redmond DE Jr, Kleber H tK (1978): (lonidine blocks acute opiate-withdrawal symptoms. Lancet 2:599-602

Grotta J (1994): Safety and tolerability of the glutamate antagonist CGS19755 in acute stroke patients. Stroke 25:255

Harris GC, Aston-Jones CA (1994): Involvement of $D_{2}$ dopa- mine receptors in the nucleus accumbens in the opiate withdrawal syndrome. Nature 371:155-157

Hayward MD, Duman RS, Nestler EJ (1990): Induction of the c-fos proto-oncogene during opiate withdrawal in the locus coeruleus and other regions of rat brain. Brain Res 525:256-266

Higgins GA, Nguyen P, Sellers EM (1992): The NMDA antagonist dizocilpine (MK801) attenuates motivational as well as somatic aspects of naloxone precipitate opioid withdrawal. Life Sci 50:PL167-PL172

Jones BE, Moore RY (1977): Ascending projections of the locus coeruleus in the rat. II. Autoradiographic study. Brain Res 127:23-53

Kimes AS, London ED (1989): Glucose utilization in the rat brain during chronic morphine treatment and naloxoneprecipitated morphine withdrawal. J Pharmacol Exp Ther 248:538-545

Kogan JH, Nestler EJ, Aghajanian GK (1992): Elevated basal firing rates and enhanced responses to 8-Br-cAMP in locus coeruleus neurons in brain slices from opiatedependent rats. Eur J Pharmacol 211:47-53

Kolb L, Himmelsbach CK (1938): Clinical studies of drug addiction, III. A critical review of the withdrawal treatments with method of evaluating abstinence syndromes. Am J Psychiatry 94:759

Korf J, Bunney BS, Aghajanian GK (1974): Noradrenergic neurons: Morphine inhibition of spontaneous activity, Eur I Pharmacol 25:165-169

Kosten TA (1994): Clonidine attenuates conditioned aversion produced by naloxone-precipitated opiate withdrawal. Eur J Pharmacol 254:59-63

Laverty R, Roth RH (1980): Clonidine reverses the increased norepinephrine turnover during morphine withdrawal in rats. Brain Res 182:482

Maldonado R, Koob GF (1993): Destruction of the locus coeruleus decreases physical signs of opiate withdrawal. Brain Res 605:128-138

Maldonado R, Stinus L, Gold LH, Koob GF (1992): Role of different brain structures in the expression of the physical morphine withdrawal syndrome. J Pharmacol Exp Ther 261:669-677

Monaghan DT, Cotman CW (1985): Distribution of N-methylD-aspartate-sensitive $\mathrm{L}-[3 \mathrm{H}]$ glutamate-binding sites in rat brain. J Neurosci 5:2909-2919

Murgan JI, Curran T (1991): Stimulus-transcription coupling in the nervous system: Involvement of the inducible proto-oncogenes fos and jun. Ann Rev Neurosci 14: 421-451

Nestler EJ (1992): Molecular mechanisms of drug addiction. J Neurosci $12: 2,439-2,450$

Nygren LG, Olson L (1977): A new major projection from locus coeruleus: The main source of noradrenergic nerve terminals in the ventral and dorsal columns of the spinal cord. Brain Res 132:85-93

(Ornstein PL, Arnold MB, Augenstein NK, Lodge D, Leander JD, Schoepp DD (1993): (3SR,4aRS,6RS,8aRS)-6-[291Htetrazol-5-yl)ethyl]decahydro-isoquinoline-3-carboxylic acid: A structurally novel, systemically active, competitive AMPA receptor antagonist. J Med Chem 36:20462048 
Pathos E, Rada P, Mark GP, Hoebel BG (1991): Dopamine microdialysis in the nucleus accumbens during acute and chronic, naloxone-precipitated withdrawal and clonidine treatment. Brain Res 566:348-350

Pert CB, Kuhar MJ, Snyder SH (1975): Autoradiographic localization of the opiate receptor in rat brain. Life Sci $16: 1,849$

Rasmussen K, Aghajanian GK (1989): Withdrawal-induced activation of locus coeruleus neurons in opiate-dependent rats: Attenuation by lesions of the nucleus paragigantocellularis. Brain Res 505:346-350

Rasmussen K, Beitner DB, Krystal JH, Aghajanian GK, Nes. tler EJ (1990): Opiate withdrawal and the rat locus coereleus: Behavioral, electrophysiologic, and biochemical correlates. J Neursoci 10:2,308-2,317

Rasmussen K, Brodsky M, Inturrisi CE (1995): NMDA antagonists and clonidine block c-fos expression during mor phine withdrawal. Synapse 20:68-74

Rasmussen K, Jacobs BL (1985): Locus coeruleus unit activit v in freely moving cats is increased following systemic mor phine administration. Brain Res 344:240-248

Rasmussen K, Krystal JH, Aghajanian GK (1991a): Excitatory amino acids and morphine withdrawal: Differential effects of central and peripheral kynurenic acid administration. Psychopharmacology 105:508-512

Rasmussen K, Fuller RW, Stockton ME, Perry KW, Sw inford RM, Ornstein PL. (1991b): NMDA receptor antagonists suppress behaviors but not norepinephrine turnover or locus coeruleus unit activity induced by opiate with drawal. Eur I Pharmacol 117:9-16

Sheng M, Greenberg ME (1990): The regulation and function of $c$-fos and other immediate early genes in the nervou. system. Neuron 4:477-485

Sonnenberg JL, Macgregor-Leon PF Curran T, Morgan II (1989): Dynamic alterations occur in the levels and com position of transcription factor A.P 1 complexes after seizure. Neuron 3:359-365

Stinus IL, Le Moal M. Koob GF (1990) . Nucleus accumbens and amygdala are possible substrates for the aversive stimulus effects of opiate withdrawal. Neuroscienst 37:767-773
Stornetta RL, Norton FE, Guyenet PG (1993): Autonomic areas of rat brain exhibit increased Foslike immunoreactivity during opiate withdrawal in rats. Brain Res 624: $19-28$

Sveinbjornsdottir S, Sander JWAS, Upton D, Thompson PJ, Patsalos PN, Hirt D, Emre M, Lowe D, Duncan JS (1993): The excitatory amino acid antagonist D-CPP-ene (SDZ EAA-494) in patients with epilepsy. Epilepsy Res 16: $165-174$

Taylor JR, Elsworth JD, Garcia EJ, Grant SJ, Roth RH, Redmond DE Jr (1988): Clonidine infusion into the locus coeruleus attenuates behavioral and neurochemical changes associated with naloxone-precipitated withdrawal. Psychopharmacology 96:121-134

Tempel A, Zukin RS (1987): Neuroanatomical patterns of the $\mu, \delta$, and $\mathrm{k}$ opioid receptors of rat brain as determined by quantitative in vitro autoradiography. Proc Natl Acad Sci USA 84:4,308-4,312

Tseng L-F, Loh HH, Wei ET (1975): Effects of clonidine on morphine withdrawal signs in the rat. Eur J Pharmacol 30:93-99

Unnerstall JR, Kopajtic TA, Kuhar MJ (1984): Distribution of a az-agonist binding sites in the rat and human central nervous system: Analysis of some functional, anatomic correlates of the pharmacologic effects of clonidine and related adrenergic agents. Brain Res 7:69-101

Valentino RJ, Wehby RG (1988): Morphine effects on locus coeruleus neurons are dependent on the state of arousal and availability of external stimuli: Studies in anesthetized and unanesthetized rats. J Pharmacol Exp Ther $244: 1,178-1,186$

Valentino RJ, Wehby RG (1989): Locus coeruleus discharge characteristics of morphine-dependent rats: Effects of naltrexone. Brain Res 488:126-134

Zhang T, Feng Y, Rockhold RW, Ho IK (1994): Naloxoneprecipitated morphine withdrawal increases pontine glutamate levels in the rat. Life Sci 55:PL25-31

Zhu Y-S, Inturrisi CE (1993): Metrazole induction of c-fos and proenkephalin gene expression in the rat adrenal and hippocampus: Pharmacologic characterization. Mol Brain Res 20:118-124 